\title{
The association of depression and anxiety with glycemic control among Mexican Americans with diabetes living near the U.S.-Mexico border
}

\author{
Darla E Kendzor ${ }^{1,2^{*}}$, Minxing Chen ${ }^{3}$, Belinda M Reininger ${ }^{4}$, Michael S Businelle ${ }^{1,2}$, Diana W Stewart ${ }^{5}$, \\ Susan P Fisher-Hoch ${ }^{4}$, Anne R Rentfro ${ }^{6}$, David W Wetter ${ }^{5}$ and Joseph B McCormick ${ }^{4}$
}

\begin{abstract}
Background: The prevalence of diabetes is alarmingly high among Mexican American adults residing near the U.S.-Mexico border. Depression is also common among Mexican Americans with diabetes, and may have a negative influence on diabetes management. Thus, the purpose of the current study was to evaluate the associations of depression and anxiety with the behavioral management of diabetes and glycemic control among Mexican American adults living near the border.

Methods: The characteristics of Mexican Americans with diabetes living in Brownsville, TX ( $N=492)$ were compared by depression/anxiety status. Linear regression models were conducted to evaluate the associations of depression and anxiety with BMI, waist circumference, physical activity, fasting glucose, and glycated hemoglobin (HbA1c).

Results: Participants with clinically significant depression and/or anxiety were of greater age, predominantly female, less educated, more likely to have been diagnosed with diabetes, and more likely to be taking diabetes medications than those without depression or anxiety. In addition, anxious participants were more likely than those without anxiety to have been born in Mexico and to prefer study assessments in Spanish rather than English. Greater depression and anxiety were associated with poorer behavioral management of diabetes (i.e., greater BMI and waist circumference; engaging in less physical activity) and poorer glycemic control (i.e., higher fasting glucose, $\mathrm{HbA1c)}$.

Conclusions: Overall, depression and anxiety appear to be linked with poorer behavioral management of diabetes and glycemic control. Findings highlight the need for comprehensive interventions along the border which target depression and anxiety in conjunction with diabetes management.
\end{abstract}

\section{Background}

Diabetes is a leading public health concern of particular relevance to Mexican Americans. Between 2003-2006, the estimated age-adjusted prevalence of diabetes among Mexican Americans adults $\geq 20$ years of age was $16.3 \%$, compared with $9 \%$ among non-Hispanic Whites [1]. Moreover, the prevalence of diabetes was recently estimated to be over 30\% among Mexican American adults residing near the U.S.-Mexico border [2]. Overweight/obesity prevalence

\footnotetext{
* Correspondence: Darla.Kendzor@UTSouthwestern.edu

${ }^{1}$ School of Public Health, The University of Texas Health Science Center, Dallas, TX, USA

${ }^{2}$ Population Science and Cancer Control Program, UT Southwestern Harold C. Simmons Cancer Center, Dallas, TX, USA

Full list of author information is available at the end of the article
}

is also alarmingly high among Mexican Americans at 81.2\%, compared with $66.7 \%$ among non-Hispanic Whites [3]. Numerous studies have shown that obesity and weight gain are linked with the onset of diabetes [4-6]. Unfortunately, Mexican Americans with diabetes, particularly those born in the U.S., are at greater risk of all-cause mortality than non-Hispanic Whites [7]. In order to address diabetes-related health disparities, focused research will be needed to better understand the physiological, psychosocial, and behavioral factors that contribute to the onset and course of diabetes among Mexican Americans.

Research indicates that the relationship between depression and diabetes is bi-directional [8-13]. Depression is associated with the development of diabetes $[8,12]$. Conversely, diabetes is associated with the development of 
depression [8-10]. Given that diabetes increases risk for depression, it is not surprising that higher rates of depression are found among diabetic patients in cross-sectional studies. Further, Mexican Americans with diabetes are more likely than other racial/ethnic groups to report symptoms of depression [14]. In fact, rates of clinically significant depressive symptoms have been reported to be as high as $40 \%$ among individuals of Mexican origin with diabetes who live on either side of the South Texas border [15]. The presence of depression in diabetes is noteworthy because depression may influence glycemic control among individuals with diabetes through physiological and behavioral pathways (for reviews, see [16-19]).

Less is known about how anxiety might influence glycemic control. Initial research suggests that adults with diabetes may have elevated levels of anxiety and greater anxiety disorder prevalence relative to the general population [20-23]. Higher levels of anxiety have also been reported among Mexicans with diabetes [24]. However, initial findings related to the impact of anxiety on glycemic control among individuals with diabetes are equivocal $[20,25,26]$. In a meta-analysis, Anderson et al. [25] reported that the relationship between anxiety and glycemic control only approached significance, though anxiety measured via diagnostic interviews was significantly associated with hyperglycemia. Since then, Gois et al. [26] reported that anxiety (measured via selfreport questionnaire) was not associated with glycemic control (i.e., HbA1c $<8$ or $\geq 8$ ). Conversely, Collins et al. [20] reported that having a high level of anxiety (measured via self-report questionnaire) was associated with poor perceived glycemic control and a greater number of diabetes complications. As such, research is needed to clarify the relations between anxiety and glycemic control in general and specifically among Latinos/Hispanics with diabetes.

Depression is associated with hyperglycemia and elevated HbA1c levels among individuals with diabetes [27-31]. Behavioral factors that contribute to poor glycemic control among individuals with diabetes may include poor adherence to recommended health behaviors including diet, weight control, physical activity, glucose monitoring, and medication regimens [17,29,32-34]. McKellar et al. [35] reported that depression had a negative impact on glucose regulation through self-care behaviors including poor adherence to diabetes dietary guidelines and poor medication adherence. Similarly, Chiu et al. [31] reported that depressive symptoms negatively influenced glycated hemoglobin (HbA1c) through diabetes-related behavioral factors including inadequate physical activity and greater body mass index (BMI). Recently, the link between depression and elevated HbA1c has been demonstrated specifically among Latinos/ Hispanics with diabetes [36]. Plausibly, the same behavioral factors may be influenced by anxiety among individuals with diabetes. Additional research is needed to characterize the relations of depression and anxiety with the behavioral management of diabetes and glycemic control among Latinos/Hispanics.

The primary purpose of the current study was to evaluate the cross-sectional associations of depression and anxiety with modifiable factors known to influence glycemic control (i.e., BMI, waist circumference, and physical activity) and more direct measures of glycemic control (i.e., HbAlc and fasting glucose) among Mexican Americans with diabetes residing near the Texas-Mexico border. Potential moderators of the associations of depression and anxiety with diabetes-related factors were also evaluated including age, gender, education, preferred language, and birth country.

\section{Subjects}

Participants were recruited from randomly selected households and invited to participate in the Cameron County Hispanic Cohort (CCHC; see [37]). Participants included in the current analyses were 492 adults $\geq 18$ years of age living in the Brownsville, Texas metropolitan area on the Texas-Mexico border. The overarching $\mathrm{CCHC}$ design and methodology have been described elsewhere [37]. A subset of all participants with diabetes were selected for the current analyses who were born either in Mexico or the U.S. Consistent with the American Diabetes Association definition of diabetes [38], participants were included in the current study if they met one or more of the following criteria: 1) told by a doctor that he/she has diabetes, 2) currently taking a medication to manage diabetes, 3) fasting glucose $\geq 126 \mathrm{mg} / \mathrm{dl}$, and/or 4) HbA1c $\geq 6.5$. The study protocol was approved by the Committee for the Protection of Human Subjects at the University of Texas Health Science Center (HSC-SPH-03-007-B), and informed consent was obtained from all participants.

\section{Methods}

\section{Measures}

\section{Socioeconomic status/demographic characteristics}

Socioeconomic and demographic characteristics assessed included age (in years), gender, years of education, birth country (Mexico or U.S.), and preferred language of study assessments (Spanish or English).

\section{Depression/anxiety}

The Center for Epidemiological Studies Depression (CES-D) questionnaire is a 20-item self-report measure of depressive symptoms over the past week [39]. Items are rated on a 4-point scale, and total scores may range from 0 to 60 . Scores $\geq 16$ indicate clinically significant distress (will be referred to as depression throughout the manuscript). The Zung Self-Rating Anxiety Scale (SAS) is a 20-item self- 
report measure of anxiety [40]. Items are rated on a 4point scale, and total scores may range from 20-80 with scores from 20-44 considered to be in the normal range. Higher scores are suggestive of greater anxiety.

\section{Anthropometric characteristics}

BMI was calculated based on weight and height measurements $\left(\mathrm{kg} / \mathrm{m}^{2}\right)$. Weight was measured without shoes to the nearest $0.2 \mathrm{~kg}$ using a portable electronic scale, and height was measured to the nearest $0.2 \mathrm{~cm}$ using a stadiometer. Waist circumference was measured with the participant in a standing position, at the level of the umbilicus to the nearest $0.2 \mathrm{~cm}$.

\section{Physical activity}

Intensity and duration of physical activity during the last 7 days was assessed using validated instrumentation of either the International Physical Activity Questionnaire (IPAQ) [41,42] or the Godin Leisure-Time Exercise Questionnaire $[43,44]$. While the physical activity questionnaire changed in response to broader study design modifications, both measures assess moderate and vigorous physical activity and allow for the calculation of metabolic equivalent values (METS) using instrumentspecific scoring recommendations $[45,46]$. METs were used as a continuous variable in the analysis. Participants who reported $>600$ MET adjusted minutes in the 7 day period were considered to have met national physical activity guidelines [47]. The physical activity assessment of some participants $(n=92)$ was not concurrent with the other measures (i.e., was not completed on the same date), and instead occurred during a later participant visit. However, additional analyses controlling for the physical activity assessment (IPAQ vs. Godin vs. delayed assessment) did not substantially change the results of the physical activity models.

\section{Glycemic control}

Fasting glucose $(\mathrm{mg} / \mathrm{dl})$ was measured using a Glucostat Analyzer (Model 27, YSI, Inc. Yellow Springs, Ohio) following a 10-hour overnight fast. Glycosylated hemoglobin was measured on frozen whole blood using the GLYCO-Tek ${ }^{\odot}$ Affinity column method Helena Laboratories, Beaumont, TX; [48] or by High Performance Liquid Chromatography. The validity of affinity chromatography for the determination of glycosylated hemoglobin has been demonstrated in comparison with other methods [49].

\section{Statistical analyses}

Cross-sectional associations of depression and anxiety with BMI, waist circumference, physical activity, fasting glucose, and HbA1c were examined among Mexican Americans with diabetes in a series of linear regression models. Scatter plots of predicted values by residuals were examined to evaluate and confirm linearity. Because of the complex survey design, models accounted for socioeconomic stratum, census tract and block, and gender (for details, see [37]). Covariates included age, gender, years of education, language of study assessment (Spanish or English), and birth country (Mexico or U.S.). Current diabetes medication use (yes or no) was included as a covariate in the models where fasting glucose or HbA1c were the outcome variables. Interactions between study covariates with depression and/or anxiety were examined to determine whether any of the variables functioned as moderators of the relations between depression/ anxiety and diabetes-related outcomes (i.e., BMI, waist circumference, physical activity, fasting glucose, and HbA1c). Interaction terms were created by multiplying depression and anxiety with each of the covariates. Interactions terms were evaluated for significance by including them individually in a linear regression model along with either depression or anxiety and all covariates. When an interaction term was found to be significant, the relationship between depression or anxiety with diabetes-related outcomes were further examined within either the natural groupings of the moderating variable (i.e., gender, assessment language, birth country) or the groups created by a median split for continuous variables (i.e., age, years of education).

\section{Results}

\section{Participant characteristics}

Participant characteristics are presented in Table 1. In summary, over $65 \%$ of participants were female, and most had less than a high school education, were born in Mexico, and elected to respond to questionnaires in Spanish rather than English. In addition, most participants were obese and appeared to have uncontrolled diabetes based on glycemic control indicators (see also [2]). Participant characteristics are presented by depression and anxiety status in Table 2 . Specifically, chi-square analyses and t-tests indicated that those who experienced significant depressive symptoms within the previous week (CES-D $\geq 16$ ) were of significantly greater age, were more likely to be female, had less education, had higher BMI and greater waist circumference, and reported less physical activity. They were also more likely to have been previously diagnosed with diabetes and to report taking diabetes medications. Similarly, participants who exhibited greater anxiety (SAS $\geq 45$ ) were of significantly greater age, more likely to be female, had less education, were more likely to have been born in Mexico, and to have completed study assessments in Spanish. In addition, anxious participants had greater BMI and waist circumference and were less likely to meet physical activity guidelines. They were also more likely to have been previously diagnosed with diabetes and to report taking diabetes medications. 
Table 1 Participant characteristics

\begin{tabular}{|c|c|c|c|c|}
\hline & $\mathbf{N}$ & Mean (SD) & $\%$ & Range \\
\hline Age (years) & 492 & $51.3(14.6)$ & - & $18-90$ \\
\hline Gender (\% Female) & 492 & - & 65.2 & - \\
\hline Education (years) & 492 & $9.1(5.2)$ & - & $0-24$ \\
\hline Birth Country (\% Mexico) & 492 & - & 66.5 & - \\
\hline Assessment Language (\% Spanish) & 492 & - & 78.0 & - \\
\hline BMI & 488 & $33.2(7.8)$ & - & 18.3-84.7 \\
\hline $\mathrm{BMI} \geq 30$ (\% Obese) & 488 & - & 65.8 & - \\
\hline Waist Circumference (cm) & 491 & $108.0(16.9)$ & - & $68-177$ \\
\hline $\begin{array}{l}\text { Physical Activity } \\
\text { (Metabolic Equivalents) }\end{array}$ & 408 & $921.1(3003.3)$ & - & $0-28,800$ \\
\hline $\begin{array}{l}\text { Not Meeting Physical Activity } \\
\text { Guidelines (\%) }\end{array}$ & 408 & - & 76.2 & - \\
\hline $\begin{array}{l}\text { Told by a doctor that you } \\
\text { have Diabetes? (\% yes) }\end{array}$ & 492 & - & 57.7 & - \\
\hline $\begin{array}{l}\text { Taking any medications } \\
\text { for Diabetes? (\% yes) }\end{array}$ & 492 & - & 50.8 & - \\
\hline Fasting Plasma Glucose (mg/dl) & 492 & $155.0(70.2)$ & - & $42-465$ \\
\hline $\mathrm{HbA} 1 \mathrm{c}$ & 384 & $8.2(2.3)$ & - & $4.6-17.7$ \\
\hline $\mathrm{HbA} 1 \mathrm{c} \geq 6.5$ (\%) & 384 & - & 85.7 & - \\
\hline CES-D Total Score & 486 & $13.0(12.3)$ & - & $0-54$ \\
\hline $\begin{array}{l}\text { CES-D Total Score } \geq 16 \\
\text { (\% Depressed) }\end{array}$ & 486 & - & 29.0 & - \\
\hline SAS Total Score & 486 & $40.5(8.7)$ & - & $21-74$ \\
\hline $\begin{array}{l}\text { SAS Total Score } \geq 45 \\
\text { (\% Mild to Extreme Anxiety) }\end{array}$ & 486 & - & 25.5 & - \\
\hline
\end{tabular}

\section{Depression, modifiable factors, and glycemic control}

After controlling for covariates (i.e., age, gender, years of education, assessment language, birth country), linear regression analyses correcting for design effects indicated that depression (as measured by the CES-D) was significantly and positively associated with BMI, $p=.054$ (model $\mathrm{R}^{2}=.03$ ) and waist circumference, $p=.005$ (model $\mathrm{R}^{2}=.06$ ), and negatively associated with physical activity (METs), $p=.007$ (model $\mathrm{R}^{2}=.03$; additional analyses indicated that results remained significant even after controlling for physical activity measure). Depression was also significantly and positively associated with fasting glucose, $p=.007$ (model $\mathrm{R}^{2}=.13$; see Table 3 ), after controlling for all previously mentioned covariates as well as medication status. Analyses indicated good fit for each model (all $p$ 's $<.05$ ). Depression was not significantly associated with HbA1c.

\section{Anxiety, modifiable factors, and glycemic control}

After controlling for covariates (i.e., age, gender, education, assessment language, birth country), linear regression analyses correcting for design effects indicated that anxiety (as measured by the SAS) was positively associated with BMI, $p=.001$ (model $\mathrm{R}^{2}=.04$ ) and waist circumference, $p<.001$ (model $\mathrm{R}^{2}=.08$ ), and negatively associated with physical activity (METs), $p=.049$ (model $\mathrm{R}^{2}=.03$; additional analyses indicated that results remained significant even after controlling for physical activity measure). Similarly, anxiety was positively associated with HbA1c, $p=.047$ (model $\mathrm{R}^{2}=.07$ ), after for controlling for all previously mentioned covariates and medication status (see Table 4). Analyses indicated good fit for each model (all $p$ 's $<.05$ ). Anxiety was not significantly associated with fasting glucose.

\section{Moderation analyses}

The interaction effects of age, gender, years of education, assessment language, and birth country with depression and anxiety on all diabetes related outcomes were evaluated (i.e., BMI, waist circumference, physical activity, fasting glucose, and HbA1c). Age, years of education, assessment language, and birth country were found to function as moderators as described below. Gender was not found to interact with depression or anxiety to predict modifiable factors related to diabetes management or glycemic control.

\section{Interactions with depression}

After controlling for all relevant covariates, there was a significant interaction effect between depression and age on fasting glucose, $\mathrm{B}=-.040 ; p=.042$. Specifically, for younger participants ( $<52$ years; median $=52$ years of age $)$ greater depression was associated with higher fasting glucose, while no association was found among participants of greater age (52+ years). Results also revealed a significant interaction between depression and education on HbA1c, $\mathrm{B}=.004 ; p=.004$. Among more educated participants $(8+$ years; median $=8$ years of education $)$, depression was positively associated with HbA1c. No association was found between depression and HbA1c among less educated participants ( $<8$ years). Depression interacted significantly with language of assessment to predict $\mathrm{HbA1c}$, $\mathrm{B}=-.004 ; p=.054$. For those who completed the assessment in English, greater depression was associated with higher HbA1c. No association between depression and HbA1c was found among those who completed the assessment in Spanish. Similarly, results revealed a significant interaction between depression and birth country to predict $\mathrm{HbA} 1 \mathrm{c}, \mathrm{B}=-.052 ; p=.013$. Among those born in the U.S., greater depression was associated with higher HbA1c. No association between depression and birth country was found among those born in Mexico. Please note that birth country (U.S. vs. Mexico) was highly correlated with preferred assessment language (English vs. Spanish; $r=.622, p<.001$ ). 
Table 2 Characteristics of Mexican Americans with diabetes by depression and anxiety status

\begin{tabular}{|c|c|c|c|c|c|c|}
\hline & \multicolumn{3}{|c|}{$\begin{array}{l}\text { Center for Epidemiologic Studies-Depression } \\
\text { (CES-D) }\end{array}$} & \multicolumn{3}{|c|}{ Zung Self-Rated Anxiety Scale (SAS) } \\
\hline & $\begin{array}{c}\text { Non-depressed } \\
\text { (score }<16 ; n=345 \text { ) }\end{array}$ & $\begin{array}{c}\text { Depressed } \\
\text { (score } \geq 16 ; n=141)\end{array}$ & $p$ & $\begin{array}{c}\text { Non-anxious } \\
\text { (score }<45 ; n=362 \text { ) }\end{array}$ & $\begin{array}{c}\text { Anxious } \\
\text { (Score } \geq 45 ; n=124)\end{array}$ & $p$ \\
\hline Age (years) & $49.79(14.66)$ & $55.10(13.97)$ & $<.001$ & $50.15(14.69)$ & $54.97(13.80)$ & .001 \\
\hline Gender (\% female) & 59.7 & 77.3 & $<.001$ & 61.3 & 76.6 & .002 \\
\hline Education (years) & $9.62(5.13)$ & $7.96(5.24)$ & .001 & $9.54(5.27)$ & $7.90(4.88)$ & .002 \\
\hline Birth Country (\% Mexico) & 64.6 & 70.2 & .238 & 63.8 & 73.4 & .052 \\
\hline Assessment Language (\% Spanish) & 76.5 & 81.6 & .224 & 75.1 & 86.3 & .010 \\
\hline BMI & $32.73(7.58)$ & $34.44(8.17)$ & .029 & $32.50(6.99)$ & $35.45(9.41)$ & $<.001$ \\
\hline BMI $\geq 30$ (\% obese) & 63.2 & 72.1 & .059 & 64.9 & 69.1 & .396 \\
\hline Waist Circumference (cm) & $106.86(16.69)$ & $111.12(17.17)$ & .012 & $106.40(15.65)$ & $113.19(19.31)$ & $<.001$ \\
\hline Physical Activity (Metabolic Equivalents) & $1124.91(3470.5)$ & $361.0(961.0)$ & .023 & $1061.6(3145.2)$ & $502.4(2583.5)$ & .101 \\
\hline Not Meeting Physical Activity Guidelines (\%) & 74.7 & 81.1 & .175 & 72.1 & 88.7 & .001 \\
\hline $\begin{array}{l}\text { Told by a doctor that you have Diabetes? } \\
\text { (\% yes) }\end{array}$ & 52.2 & 71.6 & $<.001$ & 52.8 & 72.6 & $<.001$ \\
\hline Taking any medications for Diabetes? (\% yes) & 47.0 & 60.3 & .008 & 45.9 & 65.3 & $<.001$ \\
\hline Fasting Plasma Glucose (mg/dl) & $151.86(67.57)$ & $162.48(75.04)$ & .129 & $151.74(67.23)$ & $164.40(76.62)$ & .082 \\
\hline $\mathrm{HbA} 1 \mathrm{c}$ & $8.2(2.3)$ & $8.3(2.5)$ & .684 & $8.1(2.3)$ & $8.5(2.5)$ & .118 \\
\hline $\mathrm{HbA} 1 \mathrm{c} \geq 6.5(\%)$ & 86.5 & 83.2 & .407 & 85.2 & 86.7 & .733 \\
\hline
\end{tabular}

Note: Means (standard deviations) are presented unless otherwise specified. The number of participants represented in each row may be lower than the numbers indicated at the top of column when there are missing data for the specific variable.

\section{Interactions with anxiety}

Results indicated a significant interaction between anxiety and age, $\mathrm{B}=1.630 ; p=.005$, such that anxiety was inversely associated with physical activity (METs) among participants of younger age $(<52$ years; median $=52$ years of age), while no association was found between anxiety and physical activity among participants of greater age ( $\geq 52$ years). In addition, results revealed a significant interaction between anxiety, $\mathrm{B}=-.071 ; p=.034$ and birth country in predicting HbA1c. Among those born in the U.S., greater anxiety was associated with higher HbA1c.
However, no association between anxiety and birth country was found among those born in Mexico.

\section{Discussion}

Overall, higher scores on measures of depression and anxiety among Mexican Americans with diabetes were associated with greater BMI and waist circumference, and engaging in less physical activity. In addition, greater depression was associated with higher fasting glucose, while greater anxiety was associated with higher HbA1c. Thus, the findings suggest that depression and anxiety

Table 3 Associations between depression and indicators of glycemic control among Mexican Americans with diabetes (unstandardized coefficients [B] and standard errors [SE] are presented)

\begin{tabular}{|c|c|c|c|c|c|c|c|c|c|c|}
\hline & \multicolumn{6}{|c|}{ Modifiable factors } & \multicolumn{4}{|c|}{ Glycemic control indicators } \\
\hline & \multicolumn{2}{|c|}{ BMI $(N=482)$} & \multicolumn{2}{|c|}{$\begin{array}{l}\text { Waist circumference } \\
\quad(\mathrm{cm} ; N=485)\end{array}$} & \multicolumn{2}{|c|}{$\begin{array}{l}\text { Physical activity } \\
\text { (METs; } N=403 \text { ) }\end{array}$} & \multicolumn{2}{|c|}{$\begin{array}{l}\text { Fasting glucose } \\
\text { (mg/dl; } N=486 \text { ) }\end{array}$} & \multicolumn{2}{|c|}{$\begin{array}{c}\text { HbA1c } \\
(N=381)\end{array}$} \\
\hline & B & SE & B & SE & B & SE & B & $\overline{\mathrm{SE}}$ & B & SE \\
\hline Age & -.010 & .026 & $.124^{*}$ & .051 & $-17.791^{*}$ & 8.845 & $-.447^{* *}$ & .167 & $-.033^{* * *}$ & .010 \\
\hline Gender $($ Male $=1$; Female $=2)$ & .945 & .715 & -2.959 & 1.683 & -595.856 & 337.471 & $-20.512^{* *}$ & 6.471 & -.379 & .256 \\
\hline Education (years) & -.029 & .084 & -.149 & .169 & -2.894 & 26.881 & .643 & .591 & -.009 & .021 \\
\hline Assessment Language ( $1=$ English; $2=$ Spanish) & -.493 & 1.241 & -2.155 & 2.573 & -53.315 & 411.599 & -.996 & 9.120 & -.333 & .367 \\
\hline Birth Country (1 = U.S.; 2 = Mexico $)$ & $-1.948^{*}$ & .859 & $-5.292^{* *}$ & 1.813 & 9.481 & 395.653 & 5.537 & 7.917 & -.027 & .283 \\
\hline Taking Diabetes Medication $(0=\mathrm{No} ; 1=$ Yes $)$ & - & - & - & - & - & - & $45.387^{* * *}$ & 5.942 & $.823^{* *}$ & .270 \\
\hline CES-D Score (depression) & $.058^{*}$ & .030 & $.159^{* *}$ & .056 & $-20.543^{* *}$ & 7.567 & $.646^{* *}$ & .237 & .017 & .010 \\
\hline
\end{tabular}

${ }^{*} p \leq .05,{ }^{* *} p \leq .01,{ }^{* * *} p \leq .001$. 
Table 4 Associations between anxiety and indicators of glycemic control among Mexican Americans with diabetes (unstandardized coefficients [B] and standard errors [SE] are presented)

\begin{tabular}{|c|c|c|c|c|c|c|c|c|c|c|}
\hline & \multicolumn{6}{|c|}{ Modifiable factors } & \multicolumn{4}{|c|}{ Glycemic control indicators } \\
\hline & \multicolumn{2}{|c|}{ BMI $(N=482)$} & \multicolumn{2}{|c|}{$\begin{array}{l}\text { Waist circumference } \\
\quad(\mathrm{cm} ; N=485)\end{array}$} & \multicolumn{2}{|c|}{$\begin{array}{l}\text { Physical activity } \\
\text { (METs; } N=403 \text { ) }\end{array}$} & \multicolumn{2}{|c|}{$\begin{array}{l}\text { Fasting glucose } \\
\text { (mg/dl; } N=486) \\
\end{array}$} & \multicolumn{2}{|c|}{$\begin{array}{c}\text { HbA1c } \\
(N=381)\end{array}$} \\
\hline & B & SE & B & SE & B & SE & B & SE & B & SE \\
\hline Age & -.015 & .025 & $.114^{*}$ & .050 & $-19.124^{*}$ & 8.352 & $-.447^{* *}$ & .169 & $-.033^{* * *}$ & .010 \\
\hline Gender $($ Male $=1$; Female $=2$ ) & .838 & .701 & -3.157 & 1.68 & $-672.833^{*}$ & 345.717 & $-19.798^{* *}$ & 6.419 & -.376 & .248 \\
\hline Education (years) & -.024 & .082 & -.144 & .163 & -.608 & 25.981 & .571 & .580 & -.012 & .021 \\
\hline Assessment Language(1 = English; 2 = Spanish) & -.800 & 1.188 & -2.944 & 2.45 & 50.556 & 404.397 & -3.521 & 9.077 & -.402 & .367 \\
\hline Birth Country (1 = U.S.; 2 = Mexico $)$ & $-1.990^{*}$ & .855 & $-5.401^{* *}$ & 1.817 & 25.134 & 393.21 & 5.477 & 7.933 & -.045 & .283 \\
\hline Taking Diabetes Medication ( $0=\mathrm{No} ; 1=$ Yes) & - & - & - & - & - & - & $45.133^{* * *}$ & 6.059 & $.793^{* *}$ & .263 \\
\hline SAS Score (Anxiety) & $.146^{* * *}$ & .044 & $.336^{* * *}$ & .090 & $-20.455^{*}$ & 10.308 & .703 & .389 & $.027^{*}$ & .014 \\
\hline
\end{tabular}

have a negative influence on the behavioral management of diabetes and glycemic control among Mexican Americans residing near the U.S.- Mexico border.

Depressed/anxious participants differed from those who were not depressed or anxious in a variety of ways. Similar to nationally representative samples [50,51], depressed/ anxious Mexican Americans with diabetes were of greater age, more likely to be female, and less educated than their non-depressed/anxious counterparts; they also had greater BMI and waist circumference, and engaged in less physical activity. In contrast with other research focused on anxiety disorder prevalence (e.g., [52]), anxious participants were more likely than non-anxious participants to have been born in Mexico than the U.S., and preferred to complete study assessments in Spanish. Perhaps this finding may be understood in the context of research indicating that acculturative stress is associated with greater anxiety and depression among Mexican Americans [53]. In addition, Breslau et al. [54] found that immigration from Mexico predicted the subsequent onset of anxiety. Plausibly, the higher levels of anxiety among Mexican-born participants may have been related to acculturative stress, though more research will be needed to understand potential links between nativity, acculturative stress, and anxiety.

Notably, age, years of education, assessment language, and birth country each functioned as moderators of the relationship between depression/anxiety with modifiable factors and glycemic control. Specifically, anxiety was inversely associated with hours of physical activity among younger participants, but not among participants $\geq 52$ years of age. Depression was positively associated with fasting glucose among younger participants, while there was no relation among older participants. Among younger participants with diabetes, only $43 \%$ (vs. $71.2 \%$ among older participants) had been told by a doctor that they had diabetes and only $36.6 \%$ (vs. $63.8 \%$ among older participants) were taking diabetes medication. Plausibly, depression may have had a greater impact on fasting glucose among those who were undiagnosed and therefore not taking any medications to control diabetes. Conversely, the fasting glucose of those taking medications to control blood sugar may be less affected by depression.

Interestingly, greater depression and anxiety were associated with higher HbA1c among participants born in the U.S., those who were more educated, and those who completed the study assessments in English. Conversely, depression/anxiety was not associated with HbA1c among those born in Mexico, those who were less educated, and those who completed the study assessments in Spanish. Taken together, one interpretation of these findings might be that glycemic control was more influenced by depression among acculturated participants than those who were less acculturated. In the current sample, those born in the U.S. had greater education than those born in Mexico (11.84 vs. 7.71 years) and similarly, those who completed study assessments in English had greater education than those who completed assessments in Spanish (13.87 vs. 7.76 years on average). Perhaps more acculturated and educated participants had a better understanding of how to influence HbA1c through behavior, as well as greater access to diabetes-related health care (through greater education) than their less acculturated and less educated counterparts. Vega et al. [55] reported that acculturation was positively associated with cardiovascular disease-related health knowledge among Mexican Americans, and that acculturation was strongly associated with education. Thus, depression may have a greater negative impact on glycemic control among individuals who are knowledgeable about diabetes care and have been actively managing their diabetes through behavior. Alternatively, it is possible that depression may be associated with dietary responses that differ by acculturation or education. More research will be needed to understand the links between nativity, language preference, education, and glycemic control. 
Given that diabetes is associated with depression and anxiety, it seems plausible that the assessment and treatment of depression and anxiety might improve selfmanagement of diabetes and glycemic control. However, in a recent review it was concluded that while psychosocial interventions may be effective for the treatment of depression among individuals with diabetes, it is not clear that such interventions have a beneficial impact on diabetes-related outcomes [56]. Similarly, the findings of initial research suggest that pharmacological treatments for depression improve mood, but have little impact on glycemic control (for a review, see [34]). Additional studies are needed to evaluate the impact of more comprehensive interventions designed to target both depression and diabetes management, and to identify other factors that are related to both mood and glycemic control. For example, recent research suggests that depression is associated with increased risk for the onset of dementia in individuals with diabetes [57]. Finally, treatments designed to increase physical activity may be particularly beneficial for the dual purpose of reducing depression and improving glycemic control [58].

The current study has several strengths and limitations. A notable strength of the study was the sample comprised entirely of Mexican Americans with diabetes who were recruited from within the community of Brownsville, TX (on the U.S.-Mexico border), thereby avoiding the bias inherent in clinic-based studies. Latinos/Hispanics are a vulnerable and understudied group as it relates to diabetes, and even less attention has been paid to the health of those living along the border. A limitation of the study was the cross-sectional design. As such, we were not able to determine whether there might be a causal relation between depression, modifiable behavioral factors, and glycemic control among Mexican Americans with diabetes. Similarly, we could not determine whether depression precedes or develops subsequent to poor glycemic control. Plausibly, modifiable factors, such as BMI and waist circumference, may mediate the relations between depression and glycemic control among Mexican Americans as in other samples (e.g., [59]). However, given the cross-sectional nature of the data these mediational relationships were not evaluated. Finally, it is notable that the physical activity measure (from which METS were calculated) changed during the course of the study (i.e., IPAQ to Godin) and some participants completed the physical activity assessment after a delay (i.e., assessment not completed concurrently with other measures) which may have impacted the findings. However, please note that depression and anxiety remained significantly related to physical activity (METs) even after controlling for the specific physical activity measure (Godin vs. IPAQ vs. delayed assessment).

\section{Conclusions}

Greater depression and anxiety were associated with poorer behavioral management of diabetes management and poorer glycemic control among Mexican Americans living near the U.S.-Mexico border. Findings highlight the need for comprehensive interventions designed to target depression and anxiety in the context of diabetes management among border residents. Understanding the psychosocial and behavioral factors associated with diabetes management among Latinos/Hispanics is a first step towards reducing and eliminating diabetes-related health disparities.

\section{Competing interest}

The authors declare that they have no conflicts of interest.

\section{Authors' contributions}

DEK was the primary author on the manuscript and also contributed to data analysis. MC conducted study analyses and contributed to manuscript preparation. MSB, DWS, ARR, and DWW contributed to study conceptualization and manuscript preparation. BMR, SPF, and JBM contributed to study conceptualization, organization of the cohort, data collection, and manuscript preparation. JBM is the Principal Investigator on the parent study, and BMR and SPF are co-investigators. All authors read and approved the final manuscript.

\section{Acknowledgements}

We thank our cohort recruitment team, particularly Rocio Uribe, Elizabeth Braunstein and Julie Ramirez. We also thank Marcela Montemayor and other laboratory staff for their contributions, Gloria Sanchez and Pablo Sanchez for our database management and Christina Villarreal for administrative support. We thank Valley Baptist Medical Center, Brownsville for providing us space for our Center for Clinical and Translational Science Clinical Research Unit. We also thank the community of Brownsville and the participants who so willingly participated in this study in their city. This work was supported by MD000170 P20 funded from the National Center on Minority Health and Health Disparities (NCMHD), and the Centers for Clinical and Translational Science Award UL1 RR024148 from the National Center for Research Resources (NCRR). Manuscript preparation was supported, in part, by American Cancer Society grants MRSGT-10-104-01-CPHPS (awarded to DEK) and MRSGT-12-114-01-CPPB (awarded to MSB), National Cancer Institute Cancer Prevention Fellowship grant R25TCA57730 (awarded to DWS), and by the University of Texas MD Anderson Cancer Center Duncan Family Institute for Cancer Prevention and Risk Assessment faculty fellowship (awarded to DWS).

\section{Author details}

${ }^{1}$ School of Public Health, The University of Texas Health Science Center, Dallas, TX, USA. ${ }^{2}$ Population Science and Cancer Control Program, UT Southwestern Harold C. Simmons Cancer Center, Dallas, TX, USA. ${ }^{3}$ Department of Biostatistics, The University of Texas MD Anderson Cancer Center, Houston, TX, USA. ${ }^{4}$ School of Public Health, The University of Texas Health Science Center, Brownsville, TX, USA. ${ }^{5}$ Department of Health Disparities Research, The University of Texas MD Anderson Cancer Center, Houston, TX, USA. ${ }^{6}$ College of Nursing, The University of Texas at Brownsville, Brownsville, TX, USA.

Received: 19 March 2013 Accepted: 12 February 2014

Published: 18 February 2014

\section{References}

1. NCHS: In Health, United States, 2011. Edited by USDHHS. Hyattsville, MD: U.S Government Printing Office; 2011:188-189. http://www.cdc.gov/nchs/data/ hus/hus11.pdf.

2. Fisher-Hoch SP, Vatcheva KP, Laing ST, Hossain MM, Rahbar MH, Hanis CL, Brown HS, Rentfro AR, Reininger BIM, McCormick JB: Missed opportunities for diagnosis and treatment of diabetes, hypertension, and hypercholesterolemia in a mexican american population, Cameron County Hispanic Cohort, 2003-2008. Prev Chronic Dis 2012, 9(8). 
3. Flegal KM, Carroll MD, Ogden CL, Curtin LR: Prevalence and trends in obesity among US adults, 1999-2008. JAMA 2010, 303(3):235-241.

4. The NS, Richardson AS, Gordon-Larsen P: Timing and duration of obesity in relation to diabetes: findings from an ethnically diverse, nationally representative sample. Diabetes Care 2012, 36(4):865-872.

5. Power $\mathrm{C}$, Thomas $\mathrm{C}$ : Changes in BMI, duration of overweight and obesity, and glucose metabolism: 45 years of follow-up of a birth cohort. Diabetes Care 2011, 34(9):1986-1991.

6. Meigs JB, Wilson PWF, Fox CS, Vasan RS, Nathan DM, Sullivan LM, D'Agostino RB: Body mass index, metabolic syndrome, and risk of type 2 diabetes or cardiovascular disease. J Clin Endocrinol Metab 2006, 91(8):2906-2912

7. Hunt KJ, Williams K, Resendez RG, Hazuda HP, Haffner SM, Stern MP. All-cause and cardiovascular mortality among diabetic participants in the San Antonio heart study: evidence against the "Hispanic paradox". Diabetes Care 2002, 25(9):1557-1563.

8. Golden SH, Lazo M, Carnethon M, Bertoni AG, Schreiner PJ, Roux AVD, Lee $\mathrm{HB}$, Lyketsos C: Examining a bidirectional association between depressive symptoms and diabetes. JAMA 2008, 299(23):2751-2759.

9. Rotella F, Mannucci E: Diabetes mellitus as a risk factor for depression: A meta-analysis of longitudinal studies. Diabetes Res Clin Pract 2013, 99(2):98-104.

10. Nouwen A, Winkley K, Twisk J, Lloyd CE, Peyrot M, Ismail K, Pouwer F: Type 2 diabetes mellitus as a risk factor for the onset of depression: $A$ systematic review and meta-analysis. Diabetologia 2010, 53(12):2480-2486.

11. Renn BN, Feliciano L, Segal DL: The bidirectional relationship of depression and diabetes: A systematic review. Clin Psychol Rev 2011, 31(8):1239-1246.

12. Rotella F, Mannucci E: Depression as a risk factor for diabetes: A metaanalysis of longitudinal studies. J Clin Psychiatry 2013, 74(1):31-37.

13. Roy T, Lloyd CE: Epidemiology of depression and diabetes: A systematic review. J Affect Disord 2012, 142(Supplement(0)):S8-S21.

14. Sorkin DH, Ngo-Metzger Q, Billimek J, August KJ, Greenfield S, Kaplan SH: Underdiagnosed and undertreated depression among racially/ethnically diverse patients with type 2 diabetes. Diabetes Care 2011, 34(3):598-600.

15. Mier N, Bocanegra-Alonso A, Zhan D, Wang S, Stoltz SM, Acosta-Gonzalez RI, Zuniga MA: Clinical depressive symptoms and diabetes in a binational border population. J Am Board Fam Med 2008, 21(3):223-233.

16. Rustad JK, Musselman DL, Nemeroff CB: The relationship of depression and diabetes: Pathophysiological and treatment implications. Psychoneuroendocrinology 2011, 36(9):1276-1286.

17. Musselman DL, Betan E, Larsen H, Phillips LS: Relationship of depression to diabetes types 1 and 2: epidemiology, biology, and treatment. Biol Psychiatry 2003, 54(3):317-329.

18. Pouwer F, Nefs G, Nouwen A: Adverse effects of depression on glycemic control and health outcomes in people with diabetes. A review. Endocrinol Metab Clin N Am 2013, 42(3):529-544.

19. Oladeji BD, Gureje O: The comorbidity between depression and diabetes. Current Psychiatry Reports 2013, 15(9):390.

20. Collins MM, Corcoran P, Perry IJ: Anxiety and depression symptoms in patients with diabetes: original article: psychology. Diabet Med 2009, 26(2):153-161.

21. Grigsby AB, Anderson RJ, Freedland KE, Clouse RE, Lustman PJ: Prevalence of anxiety in adults with diabetes: A systematic review. J Psychosom Res 2002, 53(6):1053-1060.

22. Smith KJ, Béland M, Clyde M, Gariépy G, Pagé V, Badawi G, Rabasa-Lhoret R, Schmitz N: Association of diabetes with anxiety: A systematic review and meta-analysis. J Psychosom Res 2013, 74(2):89-99.

23. Fisher L, Skaff MM, Mullan JT, Arean P, Glasgow R, Masharani U: A longitudinal study of affective and anxiety disorders, depressive affect and diabetes distress in adults with type 2 diabetes. Diabet Med 2008 25(9):1096-1101

24. Tovilla-Zárate $C$, Juárez-Rojop I, Peralta Jimenez $Y$, Jiménez MA, Vázquez $S$, Bermúdez-Ocaña D, Ramón-Frías T, Genis Mendoza AD, García SP, Narváez LL: Prevalence of anxiety and depression among outpatients with type 2 diabetes in the Mexican population. PLOS ONE 2012, 7(5):e36887

25. Anderson RJ, De Groot M, Grigsby AB, McGill JB, Freedland KE, Clouse RE, Lustman PJ: Anxiety and poor glycemic control: A meta-analytic review of the literature. Int J Psychiatry Med 2002, 32(3):235-247.

26. Gois C, Dias V, Raposo J, do Carmo I, Barbosa A: Vulnerability to stress, anxiety and depressive symptoms and metabolic control in Type 2 diabetes. BMC Res Notes 2012, 5(1):271.
27. Papelbaum M, Moreira RO, Coutinho W, Kupfer R, Zagury L, Freitas S, Appolinário JC: Depression, glycemic control and type 2 diabetes. Diabetol Metab Syndr 2011, 3(1):26.

28. Papelbaum M, Lemos HM, Duchesne M, Kupfer R, Moreira RO, Coutinho WF: The association between quality of life, depressive symptoms and glycemic control in a group of type 2 diabetes patients. Diabetes Res Clin Pract 2010, 89(3):227-230.

29. Dirmaier J, Watzke B, Koch U, Schulz H, Lehnert H, Pieper L, Wittchen HU: Diabetes in primary care: prospective associations between depression, nonadherence and glycemic control. Psychother Psychosom 2010, 79(3):172-178.

30. Lustman PJ, Anderson RJ, Freedland KE, Groot MD, Carney RM, Clouse RE: Depression and poor glycemic control. Diabetes Care 2000, 23(7):934

31. Chiu CJ, Wray LA, Beverly EA, Dominic OG: The role of health behaviors in mediating the relationship between depressive symptoms and glycemic control in type 2 diabetes: A structural equation modeling approach. Soc Psychiatry Psychiatr Epidemiol 2010, 45(1):67-76.

32. Lin EHB, Katon W, Von Korff M, Rutter C, Simon GE, Oliver M, Ciechanowski $P$, Ludman EJ, Bush T, Young B: Relationship of depression and diabetes self-care, medication adherence, and preventive care. Diabetes Care 2004, 27(9):2154-2160

33. Gonzalez JS, Safren SA, Delahanty LM, Cagliero E, Wexler DJ, Meigs JB, Grant RW: Symptoms of depression prospectively predict poorer self-care in patients with Type 2 diabetes. Diabet Med 2008, 25(9):1102-1107.

34. Egede LE, Ellis C: Diabetes and depression: Global perspectives. Diabetes Res Clin Pract 2010, 87(3):302-312

35. McKellar JD, Humphreys K, Piette JD: Depression increases diabetes symptoms by complicating patients' self-care adherence. Diabetes Educ 2004, 30(3):485-492.

36. Fortmann AL, Gallo LC, Philis-Tsimikas A: Glycemic control among Latinos with type 2 diabetes: The role of social-environmental support resources. Health Psychol 2011, 30(3):251-258.

37. Fisher-Hoch SP, Rentfro AR, Salinas JJ, Pérez A, Brown HS, Reininger BM, Restrepo BI, Wilson JG, Hossain MM, Rahbar MH, et al: Socioeconomic status and prevalence of obesity and diabetes in a Mexican American community, Cameron County, Texas, 2004-2007. Prev Chronic Dis 2010, 7(3):A53.

38. ADA: Standards of medical care in diabetes-2010. Diabetes Care 2010, 33(SUPPL. 1):S11-S61.

39. Radloff LS: The CES-D Scale: A self-report depression scale for research in the general population. Appl Psychol Meas 1977, 1(3):385-401.

40. Zung WW: A rating instrument for anxiety disorders. Psychosomatics 1971, 12(6):371-379.

41. Craig CL, Marshall AL, Sjöström M, Bauman AE, Booth $M L$, Ainsworth $B E$, Pratt $M$, Ekelund $U$, Yngve A, Sallis JF, et al: International physical activity questionnaire: 12-Country reliability and validity. Med Sci Sports Exerc 2003, 35(8):1381-1395.

42. Fogelholm M, Malmberg J, Suni J, Santtila M, Kyröläinen $H$, Mäntysaari M, Oja P: International physical activity questionnaire: Validity against fitness. Med Sci Sports Exerc 2006, 38(4):753-760.

43. Godin G, Shephard RJ: A simple method to assess exercise behavior in the community. Can J App/ Sport Sci 1985, 10(3):141-146.

44. Godin G, Shephard RJ: Godin leisure-time exercise questionnaire. Med Sci Sports Exerc 1997, 29(6):36-38.

45. Godin G: The godin-shephard leisure-time physical activity questionnaire, Volume 4. 2011

46. Guidelines for Data Processing and Analysis of the International Physical Activity Questionnaire (IPAQ). [http://www.ipaq.ki.se/scoring.pdf]

47. USDHHS: In 2008 Physical activity guidelines for Americans. Edited by USDHHS. 2008. http://www.health.gov/paguidelines/pdf/paguide.pdf.

48. Helena GLYCO-Tek Affinity Column Method. [http://www.helena.com/ Procedures/Pro025Rev9.pdf]

49. Klenk DC, Hermanson GT, Krohn RI, Fujimoto EK, Mallia AK, Smith PK England JD, Wiedmeyer HM, Little RR, Goldstein DE: Determination of glycosylated hemoglobin by affinity chromatograpy: Comparison with colorimetric and ion-exchange methods, and effects of common interferences. Clin Chem 1982, 28(10):2088-2094.

50. Gonzalez O, Berry JT, McKnight-Eily LR, Strine T, Edwards VJ, Croft JB: Current depression among adults - United States, 2006 and 2008. MMWR Morb Mortal Wkly Rep 2010, 59(38):1229-1235.

51. Zhao G, Ford ES, Li C, Tsai J, Dhingra S, Balluz LS: Waist circumference, abdominal obesity, and depression among overweight and obese U.S. 
adults: national health and nutrition examination survey 2005-2006. BMC Psychiatry 2011, 11(1):130-138.

52. Alegría M, Canino G, Shrout PE, Woo M, Duan N, Vila D, Torres M, Chen CN, Meng XL: Prevalence of mental illness in immigrant and non-immigrant U.S. Latino groups. Am J Psychiatry 2008, 165(3):359-369.

53. Crockett LJ, Iturbide MI, Torres Stone RA, McGinley M, Raffaelli M, Carlo G: Acculturative stress, social support, and coping: Relations to psychological adjustment among Mexican American college students. Cult Divers Ethn Minor Psychol 2007, 13(4):347-355.

54. Breslau J, Aguilar-Gaxiola S, Borges G, Castilla-Puentes RC, Kendler KS, Medina-Mora M-E, Su M, Kessler RC: Mental disorders among Englishspeaking Mexican immigrants to the US compared to a national sample of Mexicans. Psychiatry Res 2007, 151(1-2):115-122.

55. Vega WA, Sallis JF, Patterson T, Joan R, Atkins C, Nader PR: Assessing knowledge of cardiovascular health-related diet and exercise behaviors in anglo- and Mexican-Americans. Prev Med 1987, 16(5):696-709.

56. Markowitz SM, Gonzalez JS, Wilkinson JL, Safren SA: A review of treating depression in diabetes: emerging findings. Psychosomatics 2011, 52(1):1-18.

57. Katon W, Lyles CR, Parker MM, Karter AJ, Huang ES, Whitmer RA: Association of depression with increased risk of dementia in patients with type 2 diabetes: The diabetes and aging study. Arch Gen Psychiatry 2012, 69(4):410-417.

58. Groot M, Doyle T, Kushnick M, Shubrook J, Merrill J, Rabideau E, Schwartz F: Can lifestyle interventions Do more than reduce diabetes risk? treating depression in adults with type 2 diabetes with exercise and cognitive behavioral therapy. Curr Diab Rep 2012, 12(2):157-166.

59. Ching-Ju C, Wray LA, Beverly EA, Dominic OG: The role of health behaviors in mediating the relationship between depressive symptoms and glycemic control in type 2 diabetes: a structural equation modeling approach. Soc Psychiatry Psychiatr Epidemiol 2010, 45(1):67-76.

doi:10.1186/1471-2458-14-176

Cite this article as: Kendzor et al:: The association of depression and anxiety with glycemic control among Mexican Americans with diabetes living near the U.S.-Mexico border. BMC Public Health 2014 14:176.

\section{Submit your next manuscript to BioMed Central and take full advantage of:}

- Convenient online submission

- Thorough peer review

- No space constraints or color figure charges

- Immediate publication on acceptance

- Inclusion in PubMed, CAS, Scopus and Google Scholar

- Research which is freely available for redistribution 